\title{
Social Determinants Related to Type 2 Diabetes Self-Care and Control Measures
}

\author{
Seyyed Mohammad Taghi Ayatollahi' ${ }^{1}$, Leila Malekmakan², Mehrab Sayadi ${ }^{3 *}$, \\ Sadegh Karami Daranjani ${ }^{4}$ and Atefeh Zare $^{5}$ \\ ${ }^{1}$ Department of Biostatistics, School of Medicine, Shiraz University of Medical Sciences, Shiraz Iran \\ ${ }^{2}$ Shiraz Nephro-Urology Research Center, Shiraz University of Medical Sciences, Shiraz, Iran \\ ${ }^{3}$ Cardio-vascular Research Center, Shiraz University of Medical Sciences, Shiraz Iran \\ ${ }^{4}$ Msc of Health Service Management, Shiraz University of Medical Sciences, Shiraz Iran \\ ${ }^{5}$ Department of Midwifery, School of Nursing and Midwifery, Shiraz University of Medical Sciences, Shiraz Iran
}

Received: January 23,2019; Accepted: February 05,2019; Published: February 26, 2019

*Corresponding author: Dr. Mehrab Sayadi, Cardio-vascular Research Center, Shiraz University of Medical Sciences, Shiraz Iran. P. O. Box: $7193635899-$ Khalili Street, Mollasdra Avenue, Shiraz, Iran, Tel: +98-917-1332917; Email: sayadi_me@yahoo.com

\section{Abstract}

Introduction: Diabetes Mellitus (DM) as a common metabolic disorder, is a controllable disease by the self-care and maintaining the blood sugar. This study is designed to investigate the social determinants of diabetes self-care and control measures.

Methods: It is an analytical cross-sectional study conducted on 310 type-2 DM patients of Shiraz University of Medical Science by convenient sampling method. Self-care behaviors data were collected by self-care scale of Toobert and Glasgow from January to April 2017. Demographic data and serum level of HbA1c were collected. Data were analyzed by SPSS 16 and the significance level was considered as 5\%.

Results: In this study, 310 patients with Mean \pm SD age of $52.11 \pm 8.20$ were investigated. Significant relationships were observed between self-care and education level $(\mathrm{p}=0.02)$ and job $(\mathrm{p}=0.005)$. Also a significant reverse relationship was observed between diabetes control and physical activity, weight management and self-care $(\mathrm{p}<0.05)$.

Conclusion: Results showed that education level and job can increase self-care especially in weight management and physical activity; therefore, increase of these factors will result in better control of diabetes. In terms of job, it was observed that retired people had more self-care which could be due to their education level and having enough time for these actions.

Keywords: Self-care; Social determinants; Type 2 Diabetes Mellitus

\section{Introduction}

Type 2 diabetes mellitus (T2DM) includes $90-95 \%$ of diabetes patients which is involving 25.3 million in USA, and 336 million all around the world [1-3]. And also reported that this number is 8\% in Iran that will reach to 42.6 million till 2030 [4]. Diabetes increases the risk for many serious health problems including kidney diseases, reduced vision, neuropathy, and cardiovascular diseases $[5,6]$.
Diabetic patients need daily monitoring of blood sugar, injection, continuous visiting with treatment staff, accurate sport, and diet programs to reach to a satisfying control. Although diabetes control and complications are costly, but in-time diagnosis and correct care based on educating the patients, its acute or chronic complications can be prevented or delayed [711].

So controlling the DM is a particular importance [12] and one of these method is self-care and maintaining the blood sugar [13]. Diabetes self-care has been defined as a series of behaviors daily conducted by patients to diabetes control as; diet adjustment, sport, medication, self-monitoring of blood sugar or urine and caring the feet. Basic self-care has been regarded as the cure for diabetes and emphasizes on change in behaviors and management of physical, social and excitement consequences of diabetes.

Studies have shown that some social determination (SD) factors as social, economic, environmental, psychological, political and cultural can cause serious problems for self-care processes [14-23].

Although contribution of patient plays an important role in the self-care programs, but all the patients do not comply with this subject and recognition of the effective factors can help the better programming. Therefore, this study is aimed to investigate some SD factors that affect self-care and control measures among diabetic patients.

\section{Material and Methods}

\section{Participants and sampling}

This study was a cross sectional that was performed in T2DM patients of Shiraz University of medical science from January to April 2017. All patients provided informed consent before the study. Required sample size was 320 patients that 
yielded with expected ratio of self-care approximately: 50\%, precision: $5 \%$, confidence level: $95 \%$, and considering the infinite population that we will reach them. Regarding the objective population structure and health centers location, each of them was considered as a district and in each district each peripheral health center located in marginal, central old places or prestigious places were considered as a cluster-head. Then, from each health center, patients were selected by convenience sampling methods. We prefer this sampling method because it is fast, the subjects are readily available. We consider having T2DM as inclusion criteria and age $\geq 30$ years. Patients who have pregnant and who unwillingness to cooperate excluded.

\section{Data collection}

Data gathering perform by one of researchers and his coworkers in health central's field. Data tools include two sections. First, demographic information collection forms which includes factors such as age, gender, height, marital status, weight, education, job, age of disease initiation, dependence on insulin, family history, blood sugar check, waist and hip circumference, and serum level of HbA1c. Second part involved a structural selfcare profile. Presence of valid tools able to evaluate the level of selfcare in different aspects (nutriment, blood sugar measurement and sport) can be found in numerous clinical researches [24, 25]. Here, we used T2DM self-management tool designed by Glasgow and Toobert in order to assess the commitment to selfcare behaviors among T2DM patients. This questionnaire has 12 statements: which evaluate understood level and feasibility of 5 functions in self-care field (blood sugar control, receiving drug, healthy food, physical activity, and compatibility) and two overall structures (feasibility in controlling the weight, reliance on ability to manage the diabetes) which measure the level of commitment in 5 fields for 7 days. Response chooses range from 0 to 7, and higher scores indicate higher performance of self-management activities. Then it was rescaled to 100 for better comparison. Each domain was calculated by sum of its items. Then it was rescaled to 100 for better comparison. In previous studies, validity and reliability of the questionnaire have been established. Content validity was tested using a panel of experts. To evaluate the structural of the instrument factor analysis was used. Internal consistency was assessed by average inter item Correlations, which were reported as acceptable (Mean $=0.47$ ). Test-retest correlations over 34 months were reported by the authors and ranged from.40 to .78. Its internal similarity coefficient in range of 0.74 to 0.78 in each question $[24,25]$. Namdari and et al. (2006) translated and confirmed the content validity and internal reliability $(\alpha=0.77)$ of this scale [26] in Persian.

\section{Statistical analysis}

Qualitative data are expressed as number and percentage, which analyzed by the Chi-square Test or Fisher Exact Test. Quantitative data, were presented as mean and standard deviation and analyzed by Pearson correlation coefficient, Independent two sample T-test, and one-way analysis of variance (ANOVA) with LSD post-hoc Test. Data were analyzed using SPSS for Windows, Version 16.0. (Chicago, SPSS Inc.) and significance level of $5 \%$ was considered.

\section{Results}

Out of 320 questionnaires 310 patients with complete medical record and good cooperation enrolled in our study. Ten questionnaires were removed because of incomplete data. Mean \pm SD age of patients was $52.11 \pm 8.20$ years (rang: 30 to 65 ). Ninety-one of them $(29.40 \%)$ were men. The ratio of women to men was 2.40 to 1.00 . Majority of the patients were married (278, $89.70 \%)$ and most of them $(172,55.50 \%)$ had primary education level, $110(35.50 \%)$ of them had secondary education to diploma and $28(9.00 \%)$ of them had university studies. majority of the patients $(196,63.20 \%)$ were housewives, them, $33(10.60 \%)$ had free jobs $26(8.40 \%)$ of them were clerk and 56 (18.00\%) were retired. Their weights varied from 35 to $110 \mathrm{~kg}$ and their height varied from 138 to $191 \mathrm{~cm}$. Body max index (BMI) of the them ranged from 14.95 to 42.42 , waist circumference varied from 55 to $136 \mathrm{~cm}$ and their hip circumference ranged from 50 to $150 \mathrm{~cm}$. Serum HbA1C varied from 4.8 to 16.2 with the mean of $8.14 \pm 1.93$ with median of 7.8 .

T-test results are presented in Table 1 for comparing self-care score in different domains and general by gender. Based on the statistical results contained in this table and the significance level obtained by t-test, there is no significant difference between the mean of self-care score in different domains in men and women.

Self-care relationship with age was measured using Pearson correlation coefficient. The results of this analysis are summarized in Table 2. The correlation coefficient of Pearson in different domains with age is given in the table. There is only a significant direct relation between the age and the ease of blood glucose check. To investigate the relation between self-care and level of education, ANOVA with LSD post hoc test was employed. The results of this analysis are listed in Table 3. According to the $p$ value recorded in this table, there is a significant difference between self-care score for different education levels. Patients with lower education levels had lower self-care scores. LSD post hoc test indicated that this difference is related to the group under the diploma and the university group $(\mathrm{p}=0.01)$. In performance domains just blood sugar check domain was difference among 3 groups and The post-hock test (LSD) showed that this difference is related to the group under the diploma and the diploma group $(\mathrm{p}=0.009)$.

In patient behavior domains in health food, physical activity frustration and diabetes management also there was a significant difference. The post-hock test showed that in the health food and physical activity domains this difference is related to the group under the diploma and the diploma group ( $p=0.008$ and $p=0.008$ respectively) and in the frustration and diabetes management domains this difference is related to the group under the diploma and the university group ( $\mathrm{p}=0.02$ and $\mathrm{p}=0.04$, respectively)

To investigate the relationship between self-care and job, ANOVA and LSD post hoc test was employed. The results of this analysis are listed in Table 4. There is a significant difference between self-care scores in job groups. In case of adaption or frustration, physical activity, receiving health food and checking blood sugar, in behavior domain, there were significant differences in different jobs. In domain of function, for receiving 
drug, there was also a significant difference. However, the other aspects of this domain had no significant difference for different job titles. In total, the difference between housewives and retired $(p=0.02)$ and free job and retired $(p=0.007)$ were significant.

The relationship between self-care and insulin receive was calculated by T-test. The average score in total domain was $67.50 \pm 9.13$ in patients who received insulin and $65.90 \pm 8.13$

\begin{tabular}{|c|c|c|c|c|}
\hline \multicolumn{2}{|c|}{ Domains } & \multicolumn{2}{|c|}{ Gender } & \multirow{2}{*}{$\begin{array}{c}\text { p-value } \\
\text { t-test }\end{array}$} \\
\hline & & Male & Female & \\
\hline \multicolumn{2}{|c|}{ Total } & $66.97 \pm 8.63$ & $66.95 \pm 8.82$ & 0.24 \\
\hline \multirow{5}{*}{ performance } & Receiving drug & $91.07 \pm 14.34$ & $90.58 \pm 15.58$ & 0.79 \\
\hline & Blood sugar check & $84.89 \pm 24.26$ & $82.53 \pm 25.60$ & 0.45 \\
\hline & Healthy food & $76.64 \pm 16.1$ & $77.65 \pm 15.73$ & 0.611 \\
\hline & Physical activity & $26.71 \pm 16.62$ & $25.39 \pm 16.21$ & 0.51 \\
\hline & Frustration & $55.09 \pm 14.39$ & $54.66 \pm 14.41$ & 0.81 \\
\hline \multirow{7}{*}{ Patient behavior } & Blood sugar check & $54.07 \pm 23.94$ & $55.89 \pm 26.25$ & 0.56 \\
\hline & Receiving drug & $61.54 \pm 24.8$ & $60.73 \pm 28.21$ & 0.81 \\
\hline & Healthy food & $56.48 \pm 19.02$ & $59.29 \pm 29.33$ & 0.65 \\
\hline & Physical activity & $58.09 \pm 22.77$ & $60.18 \pm 22.09$ & 0.18 \\
\hline & Frustration & $65.27 \pm 24.37$ & $61.10 \pm 25.6$ & 0.25 \\
\hline & Weight management & $65.71 \pm 22.76$ & $62.19 \pm 25.75$ & 0.77 \\
\hline & Diabetes management & $81.27 \pm 13.15$ & $80.80 \pm 12.15$ & 0.98 \\
\hline
\end{tabular}

in those who did not received insulin this difference was not statistically significant $(\mathrm{p}=0.110$ and $\mathrm{t}=1.57)$. According to Pearson correlation coefficient, the correlation between self-care score and HbA1c level was calculated whose results are listed in Table 5. According to this table, there is a reverse and significant relationship between self-care score and $\mathrm{HbA1c}$, in a way that those with higher self-care score, have lower HbA1c level (their diabetes is under control).

\begin{tabular}{|c|c|c|c|}
\hline \multicolumn{2}{|c|}{ Domains } & Pearson's correlation coefficient & p-value \\
\hline \multirow{5}{*}{ performance } & Receiving drug & 0.102 & 0.07 \\
\hline & Blood sugar check & 0.020 & 0.07 \\
\hline & Healthy food & 0.063 & 0.26 \\
\hline & Physical activity & -0.015 & 0.79 \\
\hline & Frustration & -0.059 & 0.30 \\
\hline \multirow{7}{*}{ Patient behavior } & Blood sugar check & 0.171 & 0.002 \\
\hline & Receiving drug & -0.016 & 0.78 \\
\hline & Healthy food & 0.058 & 0.305 \\
\hline & Physical activity & 0.052 & 0.36 \\
\hline & Frustration & 0.060 & 0.25 \\
\hline & Weight management & 0.045 & 0.43 \\
\hline & Diabetes management & 0.027 & 0.63 \\
\hline \multicolumn{2}{|c|}{ Total } & 0.078 & 0.16 \\
\hline
\end{tabular}




\begin{tabular}{|c|c|c|c|c|c|}
\hline \multirow{2}{*}{\multicolumn{2}{|c|}{ Domains }} & \multicolumn{3}{|c|}{ Education level } & \multirow{2}{*}{$\begin{array}{l}\text { p-value } \\
\text { ANOVA }\end{array}$} \\
\hline & & Under diploma & Diploma & University & \\
\hline \multicolumn{2}{|c|}{ Total } & $65.85 \pm 9.06$ & $67.67 \pm 8.54$ & $70.14 \pm 6.89$ & 0.02 \\
\hline \multirow{5}{*}{ performance } & Receiving drug & $90.0 \pm 15.67$ & $90.91 \pm 14.35$ & $90.18 \pm 16.08$ & 0.97 \\
\hline & Blood sugar check & $86.19 \pm 21.75$ & $78.18 \pm 29.05$ & $84.82 \pm 26.43$ & 0.03 \\
\hline & Healthy food & $78.7 \pm 14.88$ & $75.45 \pm 16.12$ & $76.56 \pm 19.33$ & 0.23 \\
\hline & Physical activity & $24.78 \pm 15.85$ & $26.64 \pm 16.76$ & $28.55 \pm 17.48$ & 0.41 \\
\hline & Frustration & $55.16 \pm 4.34$ & $53.84 \pm 4.72$ & $56.19 \pm 13.38$ & 0.65 \\
\hline \multirow{7}{*}{ Patient behavior } & Blood sugar check & $54.3 \pm 24.80$ & $58.55 \pm 26.77$ & $49.29 \pm 24.63$ & 0.16 \\
\hline & Receiving drug & $58.84 \pm 27.75$ & $62.73 \pm 26.19$ & $67.16 \pm 27.33$ & 0.23 \\
\hline & Healthy food & $55.81 \pm 18.36$ & $62.06 \pm 20.72$ & $60.71 \pm 16.48$ & 0.02 \\
\hline & Physical activity & $56.98 \pm 22.89$ & $64.18 \pm 21.12$ & $60 \pm 21.08$ & 0.02 \\
\hline & Frustration & $60.70 \pm 25.58$ & $62.36 \pm 25.23$ & $72.14 \pm 24.22$ & 0.04 \\
\hline & Weight management & $61.16 \pm 24.53$ & $65.09 \pm 25.62$ & $68.57 \pm 23.99$ & 0.21 \\
\hline & Diabetes management & $79.43 \pm 13.22$ & $82.31 \pm 13.80$ & $84.82 \pm 11.06$ & 0.04 \\
\hline
\end{tabular}

\begin{tabular}{|c|c|c|c|c|c|c|}
\hline \multirow{2}{*}{\multicolumn{2}{|c|}{ Domains }} & \multicolumn{4}{|c|}{ job } & \multirow{2}{*}{$\begin{array}{l}p \text {-value } \\
\text { ANOVA }\end{array}$} \\
\hline & & Housewife & Clerk & Free job & Retired & \\
\hline \multicolumn{2}{|c|}{ Total } & $66.46 \pm 8.63$ & $66.39 \pm 6.82$ & $63.91 \pm 8.32$ & $70.28 \pm 9.56$ & 0.005 \\
\hline \multirow{5}{*}{ Performance } & Receiving drug & $89.86 \pm 16.16$ & $95.67 \pm 8.61$ & $84.77 \pm 17.16$ & $94.87 \pm 10.6$ & 0.006 \\
\hline & Blood sugar check & $82.84 \pm 25.02$ & $87.5 \pm 25.98$ & $85.94 \pm 18.17$ & $81.03 \pm 28.89$ & 0.66 \\
\hline & Healthy food & $77.23 \pm 15.89$ & $78.84 \pm 20.46$ & $75.97 \pm 10.77$ & $77.90 \pm 15.89$ & 0.90 \\
\hline & Physical activity & $24.97 \pm 16.65$ & $32.00 \pm 14.85$ & $23.97 \pm 17.41$ & $26.76 \pm 14.78$ & 0.18 \\
\hline & Frustration & $54.61 \pm 14.35$ & $56.15 \pm 5.22$ & $53.54 \pm 2.26$ & $55.47 \pm 15.47$ & 0.89 \\
\hline \multirow{7}{*}{ Patient behavior } & Blood sugar check & $55.20 \pm 25.61$ & $43.85 \pm 21.18$ & $49.75 \pm 21.51$ & $65.00 \pm 26.49$ & 0.001 \\
\hline & Receiving drug & $59.80 \pm 27.91$ & $56.15 \pm 24.01$ & $56.25 \pm 22.39$ & $70.00 \pm 27.23$ & 0.03 \\
\hline & Healthy food & $58.7 \pm 15.02$ & $54.10 \pm 17.31$ & $51.45 \pm 18.41$ & $63.69 \pm 20.17$ & 0.02 \\
\hline & Physical activity & $59.39 \pm 21.9$ & $60 \pm 21.90$ & $50.62 \pm 20.93$ & $66.43 \pm 22.91$ & 0.01 \\
\hline & Frustration & $60.82 \pm 25.04$ & $66.92 \pm 21.86$ & $58.12 \pm 26.08$ & $67.86 \pm 26.60$ & 0.16 \\
\hline & Weight management & $61.53 \pm 25.45$ & $63.08 \pm 21.68$ & $59.38 \pm 21.24$ & $71.43 \pm 25.25$ & 0.05 \\
\hline & $\begin{array}{c}\text { Diabetes } \\
\text { management }\end{array}$ & $80.46 \pm 13.04$ & $79.80 \pm 12.83$ & $79.03 \pm 12.98$ & $84.22 \pm 12.7$ & 0.19 \\
\hline
\end{tabular}




\begin{tabular}{|c|c|c|c|}
\hline \multicolumn{2}{|c|}{ Domains } & Pearson's correlation coefficient & p-value \\
\hline \multirow{5}{*}{ performance } & Receiving drug & -0.033 & 0.58 \\
\hline & Blood sugar check & -0.030 & 0.61 \\
\hline & Healthy food & 0.002 & 0.96 \\
\hline & Physical activity & 0.018 & 0.76 \\
\hline & Frustration & 0.104 & 0.08 \\
\hline \multirow{7}{*}{ Patient behavior } & Blood sugar check & -0.199 & 0.001 \\
\hline & Receiving drug & -0.069 & 0.25 \\
\hline & Healthy food & -0.064 & 0.28 \\
\hline & Physical activity & -0.008 & 0.88 \\
\hline & Frustration & -0.112 & 0.06 \\
\hline & Weight management & -0.079 & 0.18 \\
\hline & Diabetes management & -0.151 & 0.01 \\
\hline & Total & -0.133 & 0.02 \\
\hline
\end{tabular}

\section{Discussion}

Self-Care Programs Composed $>90 \%$ Of Blood Sugar Control Programs In T2DM. Environmental And Social Factors Stopped 85\% Of Diabetic Patients From Following Their Care Behaviors [27]. Numerous Studies Have Shown That Social Determinants Can Influence Self-Care And Diabetes Control $[28,29]$. Identification Of Effective Factors Of Self-Care And Diabetes Control In Each Region Can Resolve The Problems For The Educators Of Self-Care Programs And Help Them To Take More Effective Steps For Enhancement Of Their Programs To Prevent From The Complications And Control Diabetes. In This Regard, Presented Study Is Aimed To Determine The Relationship Between Social Determinant And Self-Care And Diabetes Control Programs In Diabetic Patients.

In This Study, We Showed That Social Factors Such As Job And Education Level Can Influence Self-Care And Diabetes Control. In Terms Of Job, The Highest Score Of Self-Care Was For Retired People Which Can Be Attributed To Several Reasons. First, Due To Having A Fixed Income, They Don't Have Serious Economic Issue And Their Job Stress Is Low Which Can Be Understood By Comparing Their Results With Those Having Free Jobs (With Lower Self-Care Scores). The Second Reason Is More Free-Time Of Retired Patients As Working Patients Have Less Free Time To Follow Their Self-Care Programs. Regarding Level Of Education, People With Higher Education Level Had Higher Self-Care And Their Diabetes Was More Under Control. This Can Be Understood From The Direct Relationship Between Self-Care Score And Education Like Previous Studies [14-16, 27, 17, 28, 18-20, 26, 29, $21,22,30,24,25,23]$. Therefore, It Can Be Said That Job Security And Having Enough Time For Management Of Diabetes Are The Bases For Reducing The Stress In Patient Which Facilitate The Behaviors And Control Diabetes More Effectively.

This Study Like Previous Studies, Indicated A Reverse Significant Relationship Between Self-Management And Serum Hba1c; More Self-Care Will Control Diabetes Better [31, 32]. However, A Reverse Interpretation Can Be Found; Patients With
Lower Hba1c, Have Better Physical And Psychological Health. Also For Justification Of Hba1c Correlation With Diabetes SelfManagement It Must Be Noted That Maybe Those With Higher Self-Management Achieved In Controlling Diabetes And Therefore They Will Have Lower Hba1c. So For Obtaining Better Life Quality, Diabetic Patients Should Follow Their Self-Care Programs Which Include Diet, Regular Sport, Regular Blood Sugar Test, Drug Follow-Up, And Caring The Feet [33].

Due To Sensitivity Of The Topic And Also Unreliability Of The Responses, Economic Condition Was Not Entered Into The Analysis. Social-Economic Position Is A Combinational Index Of Education Level And Income. People Normally Respond More Reliably To Questions About Their Jobs And Education. It Must Be Noted That People's Income Differs From Their Salary And Is Generally Higher Than Monthly Salary. In Many Countries Including Iran, The Respond To Income Are Not Real And The Best Method For Measuring This Index Is A Challenge. Therefore, In This Study, Although These Data Were Collected, But Due To Unreliability Of The Data, The Information Regarding The Economic Level Was Not Entered Into The Statistical Analysis. Some Sociology Researchers Believe That Social Condition Reflects Economic Condition As Well. However, In Some Rare Cases, Economic Condition Is Not A Function Of Social Situation And Hence Some Studies Investigated Economic Condition Beside The Social Condition And Revealed That Social Factors Such As Economic-Social Ones Are Significantly Associated With Diabetes, Self-Care, And Related Consequences. They Also Showed That Diabetes Complications Are Related To High Economic And Social Condition And Also High Self-Efficiency. Similar Studies Also Revealed That Low Social Position And Lower Education Level Could Result In Higher Death And More Rate Of Diabetes [34, 35].

Education Level Also Reflects Economic Condition And Can Be Regarded As A Basis For Gaps In Receiving Health Services And Therefore, General Health Condition. In This Study, Similar To Other Studies, It Was Indicated That Education Affects SelfCare From One Hand And Is Also Effective On Diabetes Control On 
The Other Hand. In Recent Decades, Interest In Health Knowledge For Collecting Enough Evidence About Personal Response To Disease Controls Via Self-Care Has Been Increased. In Recent Two Decades, Studies Have Shown That Health Knowledge Can Increase Personal Responsiveness And People's Management And Disease Control Ability Through Self-Care. Health Knowledge, Itself, Is Under The Influence Of Education Level [36]. In Present Study, The Majority Of Patients Have Primary School Education. Previous Studies Showed That People With High Social-Economic Position Preferred Private Health Centers To Public Ones [37].

This Study Also Showed No Significant Relationship Between Insulin Treatment And Diabetes Self-Management. This Study Was Designed On A Statistically Acceptable Sample And Proper Cooperation Was Done By Health Centers' Staff. Data Collection Tools Were Also Reliable And Accurate; However, There Were Some Weak Points Which Were Highlighted After Analysis. For Example, This Study Was Only Conducted On Public Centers Whose Referring Patients Did Not Involve Extensive Social And Economic Classes. Therefore, It Is Suggested To Consider This Point And Design A Research With Diabetic Patients Of Public And Private Health Centers Will Be Included Or Change The Sampling Method In A Way That This Drawback Could Be Adjusted.

\section{Conclusion}

Results showed that education level and job can increase self-care especially in weight management and physical activity; therefore, increase of these factors will result in better control of diabetes. In terms of job, it was observed that retired people had more self-care which could be due to their education level and having enough time for these actions.

\section{Acknowledgments}

The Vice-Chancellery of Research and Technology of Shiraz University of Medical Sciences (SUMS) financially supported this study (grant number: 16337). Authors would like to appreciate cooperation of no communicable unite of health vice of SUMS especially its diabetes experts in particular environmental experts who help us in data collection.

\section{Conflicts of interest statement}

The authors declare that they have no conflict of interest.

\section{References}

1. Sultan S, Attali C, Gilberg S, Zenasni F, Hartemann A. Physicians' understanding of patients' personal representations of their diabetes: accuracy and association with self-care. Psychology \& health. 2011;26(sup1):101-117. Doi: 10.1080/08870441003703226

2. Moons KG, Altman DG, Vergouwe Y, Royston P. Prognosis and prognostic research: application and impact of prognostic models in clinical practice. Bmj. 2009;338:b606. Doi: 10.1136/bmj.b606

3. Urania Dafni. Landmark analysis at the 25-year landmark point. Circulation: Cardiovascular Quality and Outcomes. 2011;4(3):363371. Doi: 10.1161/CIRCOUTCOMES.110.957951

4. WHO Danaiot WHO at IDF. 2004
5. Alvarez EO, Beauquis J, Revsin Y, Banzan AM, Roig P, De Nicola, AF et al. Cognitive dysfunction and hippocampal changes in experimental type 1 diabetes. Behavioural brain research. 2009;198(1):224-230. Doi: 10.1016/j.bbr.2008.11.001

6. Home PD. Impact of the UKPDS-an overview. Diabetic Medicine. 2008;25(2):2-8. Doi: 10.1111/j.1464-5491.2008.02501.x

7. Khamseh M, Arezo Monavari, Mojtaba Malek, Gita Shafiee, Hamidreza Baradaran. Health-related quality of life in patients with type 1 diabetes (In Persian). 2011:249-55.

8. Khaw KT, Wareham N, Bingham S, Luben R, Welch A, Day N. Association of hemoglobin A1c with cardiovascular disease and mortality in adults: the European prospective investigation into cancer in Norfolk. Annals of internal medicine. 2004;141(6):413-420.

9. Monaban F, Sands G, NeighBors M, Merek G. Phipps medical-surgical nursing. Philadelphia; Elsevier Mosby: 2007.

10. Sabatier R, Eymard JC, Walz J, Deville JL, Narbonne H, Boher JM, et al. Could thyroid dysfunction influence outcome in sunitinib-treated metastatic renal cell carcinoma? Annals of oncology. 2011;23(3):714721. Doi: $10.1093 /$ annonc/mdr275

11. Zheng J, Cheng J, Zhang Q Qi C, Wang T, Xiao X. Association between glycosylated hemoglobin level and cardiovascular outcomes in diabetic patients after percutaneous coronary intervention. Medicine. 2016;95(19): e3696. Doi: 10.1097/MD.0000000000003696

12. Saadatjoo SA, Rezvanee MR, Tabyee SH, Oudi D. Life quality comparison in type 2 diabetic patients and none diabetic persons. Modern Care Journal. 2012;9(1):24-31.

13. Ratner R, Goldberg R, Haffner S, Marcovina S, Orchard T, Fowler S, et al. American Diabetes Association. Impact of intensive lifestyle and metformin therapy on cardiovascular disease risk factors in the diabetes prevention program. Diabetes care. 2005;28(4):888-894.

14. Agardh E, Allebeck P, Hallqvist J, Moradi T, Sidorchuk A. Type 2 diabetes incidence and socio-economic position: a systematic review and metaanalysis. International journal of epidemiology. 2011;40(3):804-818. Doi: $10.1093 /$ ije/dyr029

15. Albert B. Health promotion by social cognitive means. Health education \& behavior. Health Educ Behav. 2004;31(2):143-164. Doi: $10.1177 / 1090198104263660$

16. Alberti H, Boudriga N, Nabli M. Factors affecting the quality of diabetes care in primary health care centres in Tunis. Diabetes research and clinical practice. 2005;68(3):237-243. Doi: 10.1016/j. diabres.2004.09.016

17. Baquedano IR, Santos MA, Teixeira CR, Martins TA, Zanetti ML. Factors related to self-care in diabetes mellitus patients attended at Emergency Service in Mexico. Revista da Escola de Enfermagem da USP. 2010;44(4):1017-1023. Doi: 10.1590/S0080-62342010000400023

18. Bonnefoy J, Morgan A, Kelly MP, Butt J, Bergman V. Constructing the evidence base on the social determinants of health: a guide. Measurement and Evidence Knowledge Network (MEKN). 2007.

19. F BA, Susan L Ettner, John Piette, Morris Weinberger, Edward Gregg, Shapiro MF et al. Socioeconomic position and health among persons with diabetes mellitus: a conceptual framework and review of the 
literature. Epidemiologic reviews 2004;26:63-77. Doi: 10.1093/ epirev/mxh002

20. Friel S, Marmot MG. Action on the social determinants of health and health inequities goes global. Annual review of public health. 2011;32:225-236. Doi:10.1146/annurev-publhealth-031210-101220

21. Rubin RR, Peyrot M, Siminerio LM. Health care and patient-reported outcomes. Diabetes care. 2006;29(6):1249-1255. Doi: 10.2337/dc052494

22. Sarkar U, Fisher L, Schillinger D. Is self-efficacy associated with diabetes self-management across race/ethnicity and health literacy? Diabetes care. 2006;29(4):823-829.

23. Walker RJ, Smalls BL, Campbell JA, Williams JL, Egede LE. Impact of social determinants of health on outcomes for type 2 diabetes: a systematic review. Endocrine. 2014;47(1):29-48. Doi: 10.1007/ s12020-014-0195-0

24. Toobert DJ, Glasgow RE. Assessing diabetes self-management: the summary of diabetes self-care activities questionnaire. Handbook of psychology and diabetes: A guide to psychological measurement in diabetes research and practice. 1994;:351-375.

25. Toobert DJ, Hampson SE, Glasgow RE. The summary of diabetes selfcare activities measure: results from 7 studies and a revised scale. Diabetes care. 200;23(7):943-950. Doi: 10.2337/diacare.23.7.943

26. Ghasemi N, Namdari K, Ghoreshian M, Amini M. The relationship between "expectationism" and "loyalty to self-care behaviors" in type II diabetes patients. Clin Phsychol Personal. 2010;1(43):1-10.

27. Asante E. Interventions to promote treatment adherence in type 2 diabetes mellitus. British journal of community nursing. 2013;18(6):267-274. Doi: 10.12968/bjcn.2013.18.6.267

28. Berkowitz SA, Baggett TP, Wexler DJ, Huskey KW, Wee CC. Food insecurity and metabolic control among US adults with diabetes Diabetes care. 2013:36(10):3093-3099. Doi: 10.2337/dc13-0570
29. Kollannoor-Samuel G, Vega-López S, Chhabra J, Segura-Pérez S, Damio G, Pérez-Escamilla R. Food insecurity and low self-efficacy are associated with health care access barriers among Puerto-Ricans with type 2 diabetes. Journal of immigrant and minority health. 2012;14(4):552-562.

30. Siebolds M, Gaedeke O, Schwedes U, SMBG Study Group. Selfmonitoring of blood glucose-psychological aspects relevant to changes in HbA1c in type 2 diabetic patients treated with diet or diet plus oral antidiabetic medication. Patient education and counseling. 2006;62(1):104-110. Doi: 10.1016/j.pec.2005.06.013

31. Persell SD, Keating NL, Landrum MB, Landon BE, Ayanian JZ, Borbas $\mathrm{C}$ et al. Relationship of diabetes-specific knowledge to selfmanagement activities, ambulatory preventive care, and metabolic outcomes. Preventive medicine. 2004;39(4):746-752. Doi: 10.1016/j. ypmed.2004.02.045

32. Xu Y. Understanding the factors influencing diabetes self-management in Chinese people with type 2 diabetes using structural equation modeling (Doctoral dissertation, University of Cincinnati). 2005.

33. Shrivastava SR, Shrivastava PS, Ramasamy J. Role of self-care in management of diabetes mellitus. Journal of Diabetes \& Metabolic Disorders. 2013;12(1):14. Doi: 10.1186/2251-6581-12-14

34. Saydah S, Lochner K. Socioeconomic status and risk of diabetes-related mortality in the US. Public health reports. 2010;125(3):377-388. Doi: $10.1177 / 003335491012500306$

35. Whiting D, Unwin N, Roglic G. Diabetes: equity and social determinants. Equity, social determinants and public health programmes. 2010;77:94

36. Berkman ND, Sheridan SL, Donahue KE, Halpern DJ, Crotty K. Low health literacy and health outcomes: an updated systematic review. Annals of internal medicine. 2011;155(2):97-107. Doi: 10.7326/00034819-155-2-201107190-00005

37. Makan LM, Moghadami M, Sayadi M, Azad HM, Sakha MA. Assessment of social determinants related to mother nd child healthcare services: a cross sectional study in Shiraz, Iran 2013. Shiraz E-Medical Journal. 2015;16(5): e26726. 